\title{
El dominio del segundo fuego
}

\author{
De luz son las palabras con las que la materia habla \\ y también las que a menudo escucha
}

En su Asamblea General de 2013, las Naciones Unidas aceptaron la recomendación de la Unesco de declarar el 2015 como "Año Internacional de la Luz y de las tecnologías basadas en ella”, para exaltar la importancia que el conocimiento de ese fenómeno físico ha tenido para la humanidad a lo largo de toda su historia, particularmente, durante el siglo XX y los albores del XXI.

Sin duda, la importancia de la luz como fenómeno natural supera en mucho nuestro interés inmediato. Los fotones fueron las primeras partículas originadas en el Big Bang, seguidos por las partículas masivas. Sin embargo, se convirtieron en los mensajeros cósmicos: la luz es absorbida y emitida por la materia, y tanto al absorberla como al emitirla, la materia cambia de estado, evoluciona. Su evolución queda impresa como un mensaje en la luz que emite, y este mensajero lo propaga hasta los confines del cosmos, a la máxima velocidad posible. Una parte importante del conocimiento científico actual consiste en los procedimientos y claves para descifrar tales mensajes, y así, dilucidar la historia completa del universo.

Con la luz que absorbe, la materia desencadena procesos internos que suelen modificar también el entorno. En nuestro planeta, la evolución más maravillosa de la materia en su relación con la luz es la vida, evolución que ahora sospechamos como algo posible en otros planetas. El dosel vegetal que cubrió la mayor parte de la superficie sólida de la tierra, especialmente en eras como el Cretácico Medio, operó como una gran antena de captación de luz para la fotosíntesis, un proceso vital no solo para la cadena trófica que asegura la supervivencia de los demás seres vivos, sino también para la regulación de los ciclos de lluvias, de las cuencas hidrográficas, de la renovación de la atmósfera. La luz y el agua hicieron posible la vida y la vida hizo habitable el planeta.

La fascinación que el hombre ha tenido por la luz pudo originarse en dos tipos de percepciones sensoriales: la vista y el tacto. Mucho esfuerzo hemos dedicado a la comprensión del mecanismo de la visión y a ampliar su capacidad mediante instrumentos, lo que dio lugar a la síntesis matemática de las leyes fundamentales que gobiernan el comportamiento de la luz, bautizadas como reflexión y refracción. También condujo a diferentes apreciaciones sobre la naturaleza misma del fenómeno, siendo la más arraigada en la historia aquella que concibe la luz como compuesta de partículas inconmensurables. Hubo que esperar hasta la revolución científica del siglo XVII para evidenciar que la luz "también a menudo incluso ondula", como lo señala Francesco María Grimaldi en su tratado de 1665 Physico-Mathesis de Lumine, Coloribus et Iride, y por ello se difracta cuando ilumina objetos suficientemente pequeños, un siglo y medio más para aceptar que la luz es en esencia una ondulación susceptible de distribuirse en franjas de interferencia, algo más de medio siglo adicional para comprender la naturaleza electromagnética de esa ondulación, clave para su interacción con la materia, que también tiene naturaleza electromagnética,y llegar a los albores del siglo XX para sorprendernos con el hecho de que, a diferencia de las ondas mecánicas, las luminosas no requieren de un medio material de soporte, lo que dejó sin sentido la convicción sobre la existencia del éter, cuyas raíces alcanzaron la Grecia clásica. La sorpresa fue aún mayor en el siglo XX, con el retorno imbatible de la concepción corpuscular de la luz, que se manifiesta con toda claridad en su absorción y emisión por la materia. Las explicaciones de la emisión de radiación producida por un cuerpo negro, de la absorción de radiación en el efecto fotoeléctrico y de la emisión de radiación a partir de un gas de átomos de hidrógeno, basadas todas en la apreciación de la luz como una composición de cuantos de energía electromagnética, que hoy denominamos fotones, se consideraron los avances científicos de mayor importancia en las décadas iniciales del siglo XX.

La asociación de la luz con el fuego tiene la fuerza de una constante histórica. La sensación térmica que produce, de naturaleza táctil, y su empleo para la cocción de alimentos jugó un papel definitivo en la supervivencia y el desarrollo de la especie. Mucho después vendría su aplicación a la fabricación de objetos de metal, que caracterizó la conformación de civilizaciones avanzadas. Uno de los pilares del salto tecnológico dado en el siglo XX, sin parangón en la historia de la humanidad, es el dominio de la electricidad y el magnetismo, particularmente en su manifestación por excelencia: la luz. Por su enorme potencial, pareciera justo considerar el conocimiento que hemos alcanzado sobre la luz como el "dominio del segundo fuego". 
Con esta separata especialmente dedicada a la celebración del Año Internacional de la Luz 2015, la Academia Colombiana de Ciencias Exactas, Físicas y Naturales se une a la efemérides mundial con la publicación de artículos inéditos de reconocidos investigadores, tanto colombianos como de otros países, en temas relacionados explícitamente con la luz. Aunque sus contribuciones constituyen una muestra puntual del amplio panorama de estudios sobre y con la luz, son en su mayoría aportes vanguardistas que ilustran particularmente el momento por el que atraviesa la investigación de esas áreas en Colombia. Se han incluido algunos artículos de cultura científica general y de crónicas para situar al lector no especializado en un contexto amplio, en el que los temas más específicos adquieren pleno sentido.

Abrimos la separata con un artículo del profesor Giorgio Matteucci, de la Universidad de Bologna (Italia), que ofrece al lector el panorama histórico de la evolución del conocimiento de la luz, el cual desemboca en el importante descubrimiento del siglo XX denominado holografía, con impacto tanto en la ciencia como en el arte. Plantea el profesor Matteucci que semejante esfuerzo ha sido motivado por una pulsión humana, presente en todas las etapas de la humanidad: la comunicación, e ilustra esta idea con los logros de la holografía realizada tanto con luz (holografía óptica) como con electrones (holografía electrónica).

Uno de los avances distintivos del siglo XX fue el desarrollo de la computación numérica, haciendo de los computadores elementos indispensables de los canales y redes de comunicación de datos. La holografía no fue ajena a ese desarrollo, como tampoco a su aplicación en la formación de imágenes microscópicas sin lentes. El profesor Jorge Garcia, de la Universidad Nacional de Colombia Sede Medellín, es un líder con reconocimiento internacional en microscopía holográfica digital y pionero del desarrollo de estos dispositivos en el país. Con su grupo, el profesor Garcia se ha hecho presente con dos importantes artículos, que incluyen el tema de frontera de las imágenes holográficas multiespectrales y la generalización de un criterio de control para la reconstrucción digital de imágenes holográficas.

Pero la comunicación requiere de la noción de realidad, la cual está ligada estrechamente con la del sentido de la visión, como lo explican los profesores de matemáticas Antonio Vélez (Universidad de Antioquia) y Juan Diego Vélez (Universidad Nacional de Colombia, Sede Medellín), al abordar los aspectos cognitivos relacionados con la visión desde una perspectiva de cultura científica no especializada.

Hoy en día denominamos informacióna aquello que, con diferentes soportes físicos (uno de ellos la luz), fluye a través de los canales de comunicación. Desde el punto de vista técnico se invierte tanto esfuerzo en asegurar la calidad de la información como en garantizar su protección, de modo que alguien distinto al destinatario específico no pueda recibir o, en último caso, comprender la información enviada por un remitente dado. Tal esfuerzo de protección ha impulsado la novedosa disciplina de la encriptación de la información en lo que va corrido del siglo XXI. Referentes internacionales de la encriptación óptica son los profesores Roberto Torroba, de la Universidad Nacional de La Plata (Argentina), y John Freddy Barrera, de la Universidad de Antioquia. En los últimos años, el profesor Barrera ha sido galardonado a nivel nacional e internacional por sus contribuciones en dicho tema. Dos artículos, fruto de su colaboración, hacen parte de esta separata.

Son diferentes las escalas involucradas en los canales y redes de comunicación. La holografía óptica y la encriptación de información óptica se desarrollan usualmente en la escala de nuestras dimensiones cotidianas, pero la microscopía holográfica digital y la holografía electrónica se realizan en las escalas micro y nanoscópica. También disponemos de información luminosa a escala astronómica o estelar, que ha sido motivo de estudio desde la antigüedad. La observación detallada de estrellas y galaxias nos ha obligado a profundizar en el conocimiento de los atributos de la luz, uno de los cuales es la correlación de orden superior. El investigador Juan Manuel González, de la Fundación Universidad Autónoma de Colombia, nos informa sobre un novedoso método para analizar las sorprendentes observaciones astronómicas reportadas por primera vez a fines de los años 50, conocidas hoy como efecto Hanbury-Brown and Twiss (HBT).

La comprensión del fenómeno luminoso no sería completa, no obstante, si no se tiene en cuenta su interacción con la materia inorgánica y orgánica, en la que su naturaleza electromagnética y cuántica se manifiesta plenamente. El artículo del destacado profesor de la Universidad de Antioquia, Carlos Duque, y sus colaboradores, reporta el estudio teórico de un problema considerado de punta, como es el comportamiento de un anillo de propiedades específicas en presencia de campos eléctricos y luminosos; así mismo, el artículo del profesor Ángel Meléndez, de la Universidad Industrial de Santander, y sus colaboradores, aborda un tema de alta tecnología para aplicaciones que involucran la luz, mientras que el investigador FanorCasasierra, de la Universidad Pedagógica y Tecnológica de Colombia, reporta el efecto de la calidad de la luz sobre las modificaciones morfogénicas de los cultivos.

No podría cerrarse una separata conmemorativa como esta sin crónicas sobre sucesos de importancia para el desarrollo de la óptica en Colombia. Los profesores Francisco Medina (Universidad de Antioquia) y Jorge Garcia (Universidad Nacional de Colombia Sede Medellín) narran el desarrollo de la óptica en Medellín, desde su iniciación con el profesor austríaco 
Peter Barlai, hasta la actualidad, cuando Medellín se ha constituido como uno de los polos de mayor productividad en óptica del país. Finalmente, la invaluable crónica del Presidente de la Academia Colombiana de Ciencias Exactas, Físicas y Naturales, Doctor Enrique Forero, quien cuenta el hecho histórico de haber conseguido reunir a los profesores David Wineland y Serge Haroche, galardonados con el Premio Nobel de Física 2012, al lado de otros investigadores de talla mundial, así como de colombianos destacados a nivel internacional, once científicos que disertaron sobre el "Año Internacional de la Luz y de las tecnologías basadas en ella" en Bogotá y en Medellín, en un evento científico sin precedentes en nuestro país.

Con esta separata especial, la Academia Colombiana de Ciencias Exactas, Físicas y Naturales entrega a la comunidad científica nacional e internacional un aporte pequeño pero muy significativo al año de conmemoración del dominio del segundo fuego, la luz, por parte del hombre.

\section{Román Castañeda Sepúlveda}

Dr.rer.nat.

Editor invitado

Miembro correspondiente

Academia Colombiana de Ciencias Exactas, Físicas y Naturales

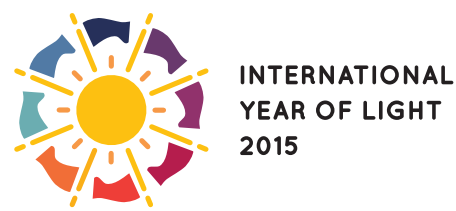

